\title{
PERAN EFIKASI DIRI TERHADAP PRESTASI DAN PERFORMANSI: META ANALISIS
}

\author{
Ratna Syifa'a Rachmahana \\ Universitas islam Indonesia
}

\begin{abstract}
This article reports on meta-analyses of the relations between self-efficacy beliefs and achievement or performance in every field. The quantitative roviow of thity studies fom eighteen articles. Results revealed positive and statistically significant relationships botween self-eficacy beliefis and achigvement or performance and persistence outcomes across a wide variety of subjects, experimental designs and assessment methods. The relationships were found to be heterogeneous across studies, and the variance in reported eff act sizes was partially explained by certain study characteristics. Implications for further research and fir intervention are discussed.
\end{abstract}

Key words: meta-analysis, self-efficacy, achievement, performance

Istilah efikasi diri pertama kali diperkenalkan oleh Bandura pada tahun 1977 dalam teorf Belajar Sosial (Bandura. $1977,1982,1986)$, Bandura mendefinisikannya sebagai keyakinan lentang sejauh mana individu memperkirakan kemampuan dirinya dalam melaksanakan suatu tugas atau tindakan yang diperlukan untuk mencapai hasil. Selanjutnya Schunk (1985) menjelaskan bahwa efikasi dirf adalah bagian dari konsep diri yang merupakan keyakinan seseorang akan kemampuannya untuk mengarahkan tugas secara efektif dan melakukan tindakan yang diperiukan.

Sebetulnya efikasi diri tidak berhubungan dengan kapasitas kemampuan individu, melainkan dengan penilaian tentang apa yang dapat dilakukan oleh individu, apapun tingkat keahlian yang dimiliklnya (Brehm \& Kassin, dalam Mun, 2000). Orang yang memiliki efikasi diri yang tinggi diyakini sebagai orang yang mampu berperilaku tertentu untuk dapat mencapai hasil yang diinginkan atau target yang ditetapkan pada situasi tersebut. Selain itu. mereka juga lebih giat dan lebih tekun dalam berusaha. Saat menghadapi kesulitan. individu ini tidak mudah cemas dan jarang kecewa, apalagi menyerah. Sebaliknya dengan orang yang memiliki efikasi dri rendah, sangat rentan dengan keraguraguan akan kemampuan dirf, sehingga kurang bisa mengarahkan perilaku sesuai tujuan dan mudah putus asa.

Prestasi adaiah hasil perubahan tingkah laku yang meliputi aspek kognitif, af ektif dan psikomotor yang merupakan tolok ukur keberhasilan. Faktor-faktor yang mempengaruhi prestasi dalam dua kelompok, yakni kelompok dari luar individu (faktor eksogen) dan dari dalam (faktor endogen). Faktor eksogen terdiri atas faktorfaktor sosial dan non sosial. Tuntutan dari orang lain misalnya, adalah contoh dari faktor sosial, sedangkan faktor non sosial meliputi keadaan alam, kesediaan alat pendukung, dan lain-lain. Adapun faktor endogen menyangkut dua faktor, yakni fissik dan psikis. Fisik meliputi kesehatan, koordinasi motorik, dan keadaan syaraf, sedangkan psikis adalah inteligensi, minat, bakat, kecemasan, 
kematangan emosional, penyesuajan diri dan efikasi diri.

Berdasarkan uraian di atas, efikasi diri adalah bagian dari faktor endogen dalam mempengaruhi prestasi seseorang. Para ahli pendidikan sangat meyakini hubungan kedua hal ini, sehingga banyak sekali dilakukan penelitian yang mengaitkan efikasi diri dengan prestasi belajar, seperti matematika (Lent,dkk., 1991; Malpass, dkk., 1999; Lioyd,dkk. 2005; Pajares \& Miller, 1994) dan bahasa (Mills,dkk. 2006; Bong. 2004) ataupun strategi belajar (Jakubowski \& Dembo, 2004).

Sejak tahun 1990-an, penelitian tentang efikasi diri banyak dilakukan pula oleh ahli non pendidikan, seperti di bidang klinis, perkembangan, industri, dan lain-lain. Efikasi diri dipercaya mempunyai pengaruh tehadap Kinerja (Opacic,2003; Luzzo, 1993; Earley \& Lituchy, 1991; Tannenbaum, dkk, 1991; Strauser dkk., 2002; Brater,dkk., 2004; Jaber \& Qutami, 1998), pengasuhan anak (Jackson \& Scheines, 2005; Holloway,dkk. 2005), konseling (Herman \& Betz, 2004; Fiorentine \& Hillhouse, 2000;Lackaye \& Margalit, 2006), dan lain-lain. Pada penelitian-penelitian tersebut, diperoleh korelasi positif yang signifikan antara efikasi diri dengan behavioral outcomes (perilaku yang dihasilkan). Peneliti mengartikannya dengan prestasi dan performansi.

Individu dengan efikasi diri yang tinggi akan berjuang tanpa mengenal lelah untuk melakukan hal-hal yang mendukung pencapaian tujuan, khususnya di dalam penyelesaian tugas. Hal ini disebabkan adanya keyakinan terhadap dirinya, bahwa ia mampu melakukan apapun tanpa ragu atau malu. Dengan demikian, usaha yang dilakukan pun akan optimal, sehingga tentu saja prestasi yang ideal bukan hal yang sulit untuk diraih.

Berdasarkan temuan-temuan hasil penelitian tersebut dan nilai penting dari efikasi diri terhadap prestasi individu, proses meta analisis ini dilakukan, sehingga akan nampak seberapa jauh pengaruh efikasi diri dalam prestasi atau performansi seseorang di berbagai bidang.

\section{DASARTEOR}

\section{Prestasi dan Performansi}

Prestasi adalah hasil usaha seseorang dalam bidang tertentu. Dalam dunia pendidikan, prestasi dilekatkan dengan proses belajar, sehingga disebut dengan prestasi belajar, sedangkan di luar dunia pendidikan, dikenal dengan istilah prestasi kerja. Adapun performansi menunjukkan pengertian yang lebih luas daripada prestasi. Dalam hal ini sering disebut dengan istilah kinerja. Semua istilah ini pada dasamya mengacu pada satu hal, yakni pencapaian suatu usaha seseorang yang terwujud dalam bentuk perilaku yang diinginkan, baik oleh individu maupun organisasi.

Dalam rangka mengetahui seberapa tinggi prestasi atau performansi, biasanya dilakukan suatu pengukuran yang menghasilkan sebuah indeks. Pencapaian indeks merupakan evaluasi proses yang melibatkan semua ranah dalam diri individu, yakni ranah kognitif, afektif dan psikomotorik. Contoh manifestasi dari hal ini adalah pernyataan Armstrong (1999), bahwa penilaian kinerja didasarkan pada knowledge, skill, expertise dan behavior individu dalam melakukan pekerjaan dengan baik.

Ada banyak hal yang mempengaruhi tinggi rendah atau baik buruknya prestasi. Semua ahli sepakat bahwa faktor penentu prestasi bisa berasal dari dalam dan luar diri seseorang. Kedua faktor saling berkaitan, dan diharapkan saling menunjang untuk memunculkan performansi atau prestasi terbaik. Dalam tulisan ini, penulis hanya mengambil salah satu faktor dari dalam individu, yakni efikasi diri.

\section{Efikasi Diri}

Bandura $(1977,1982$, 1986) telah membangun sebuah kerangka teori yang memberikan pencerahan terhadap peran dari pola pikir yang bertumpu pada pemahaman diri dalam perubahan perilaku manusia. Berdasarkan konsep ini. perubahan perilaku dicapai melampaui keberagaman metode sebagal awal 
petunjuk, model, persuasi dan reduksi kecemasan yang merupakan kreasi pencapaian efikasi pada manusia. Efikasi diri dihipotesiskan mempengaruhi pitihan daiam memilih aktivitas perilaku, pengeiuaran effort, ketekunan dalam menghadapi rintangan dan performansi daiam penyelesaian tugas.

Terdapat tiga komponen yang memberikan dorongan bagi terbentuknya efikasi diri, yaitu :

1. Outcome Expectancy (Pengharapan hasii), adaiah harapan akan kemungkinan hasil dari periiaku. Harapan tersebut berdasarkan keyakinan adanya hubungan yang menjembatani kinerja tugas dengan hasii. Harapan ini berwujud perkiraan kognitif tentang kemungkinan hasili yang akan diperoieh dan kemungkinan tercapainya tujuan melaiui keberhasilan kinerja tersebut akan bertungsi sebagai penguat.

2. Efficacy-Expectancy (Pengharapan efikasi), yaitu harapan atas muncuinya perilaku yang dipengaruhi oleh persepsi individu pada kemampuan kinerjanya yang berkaitan dengan hasii. Pengharapan efikasi cenderung digeneralisasikan pada situasi atau tugas lain yang sama dan berhubungan dengan situasi dan tugas sebelumnya. Bila seseorang sering mengaiami kegagalan pada suatu tugas tertentu maka ia cenderung memiliki efikasi diri yang rendah pada tugas iain. Demikian pula apabila ia mendapatkan kebeihasilan maka efikasi dirinya akan meningkat pada semua tugas yang memiliki keminipan.

3. Outcome Value (Nilai hasii), yaitu nilai kebermaknaan atas hasil yang diperoleh individu. Nilai hasil yang sangat berarti akan memberikan pengaruh secara kuat pada motivasi individu untuk mendapatkannya kembali.

Lebih ianjut Bandura (1982) merumuskan adanya tiga dimensi dajam efikasi diri, yakni:

a. Magnitude, berhubungan dengan tingkat kesulitan yang dilakukan. Apabila dihadapkan pada tugas-tugas yang disusun menurut tingkat kesuiltan, maka efikasi diri akan diarahkan pada tugas-tugas yang mudah, sedang atau sulit sesuai dengan batas kemampuan yang dirasakan untuk memenuhi tuntutan peri laku yang dibutuhkan bagi masing-masing tingkat.

b. Generality, berkaitan dengan luas bidang yang dilakukan. Efikasi difi pada individu bisa terbatas pada bidang tugas tertentu saja, sementara individu iain meliputi beberapa bidang tugas.

c. Strength, berhubungan dengan kemantapan atau tingkat keyakinan individu. individu dengan efikasi diri yang lemah akan lebih mudah menyerah pada pengalamanpengalaman ketidakbethasiian, sementara individu yang kuat efikasi dirinya akan tetap berusaha meskipun menemui pengaiaman yang menghambat.

Beberapa teori dikenali teiah memiliki rełevansi terhadap teori efikasi diri, dalam rangka menjadikannya sebagai prediktor terhadap pefformansi dan prestasi. Usaha pertama dilakukan okh Hackett dan Betz (1981) yang menemukan hubungan efikasi diri dengan pemiihihan karier dan pengambiian keputusan. Selanjutnya Lent dkk.(1984) membuktikan bahwa efikasi diri dapat dijadikan prediktor atas ketekunan dan kesuksesan pad a siswa d beberapa jurusan. Berdasarkan hasil temuan tersebut, teori efikasi diri dianggap lebih kuat daripada model teori lain dalam menjelaskan dan memperkirakan performansi akademik di kalangan siswa dan mahasiswa (Siegel, Galassi \& Ware, 1985).

Schunk (1985, 1987) memfokuskan penelitian terhadap kemampuan kognitif pada anak-anak usia dini, yang kemudian menghadirkan sebuah model motivasi pembelajaran, di mana efikasi diri adalah pemegang peranan penting. Schunk memaparkan bahwa sebagaimana bakat dan pengalaman pendidikan sebelumnya, anak mengembangkan efikasi dan harapan capalan hasil usaha pada tugas-tugas kognitif secara berbeda. Harapan inilah yang memunculkan motivasi, dan berimbas pada usaha yang dilakukan, dan akhirnya berpengaruh pula terhadap hasil. Pengaruh 
balik ini pada titk tertentu akan menjadi sebuah efikasi dan pengharapan akan hasil yang optimal. Proses ini secara terusmenerus akan menghasilkan sebuah pengaruh balk yang berkesinambungan.

\section{Hipotesis}

Ada korelasi positif antara efikasi diri dan prestasi atau performansi seseorang. Semakin tinggi efikasi diri maka semakin tinggi juga perfomansi atau prestasi yang dimilikj.

\section{METODE}

\section{Seleksl Hasil Penelitian}

Ada 3 (tiga) teknik yang dilakukan dalam langkah in untuk molakukan meta analisis. Pertama, pencarian data artikel juma! melalui penelusuran jumal yang menjadi koleksi Perpustakaan Fakultas Psikologi UGM dan lewat meda komputer, yaitu dengan menggunakan program EBSCO, Questia, dan ProQuest. Kata kunci yang digunakan untuk teknik ini adalah selfeficacy, achievement, dan perfomance.

Kedua, memeriksa kelengkapan dari isi studi, seperti jumlah sampel, pengukuran efikasi diri (sebagai variabel bebas), pengukuran prestasi atau performansi (sebagai variabel tergantung), dan hasil analisis yang diperoleh.

Ketiga, membuat tabulasi hasil penelusuran dengan memasukkan informasi-informasi pendukung yang penting untuk meta analisis, seperti karakteristik subjek, jenis prestasi atau performansi, dan lain-lain.

Hasil seleksi menemukan 30 (tiga puluh) studi yang bisa dianalisis, yang berasai dari 19 artikel. Tiga studl merupakan studi eksperimen, dan 27 yang lain adalah studi survey. Dengan demikian diperoleh 27 nilai $r$ dan 3 nilai $F$ (yang kemudian ditransformasi menjadi nilai r).

\section{Prosedur Meta analisis}

Analisis data dengan menggunakan teknik meta analisis (Hunter-Schmidt, 1990) dilakukan dengan langkah-langkah sebagai berikut:

1. Merubah persamaan aljabar đari nilai $F$ menjadir

2. Bare Bones Meta analyses untuk mencari nilai koreksi kesalahan sampel, yang dilakukan dengan:

a. Menghitung mean korelasi populasì,

b. Menghitung variansixy,

c. Menghitung varians kesalahan pengambilansampoi,

d. Dampak pengambilan sampel.

3. Atifak selain kesalahan pengambilan sampel, yaitu untuk koreksi kesalahan pengukuran, yang dliakukan dengan:

a Menghitungreratagabungan,

b Menghitung koreksi kesalahan pengukuran pada $x$ dan $y$, yaitu koreksi yang sesungguhnya dari populasi,

c. Jumlah koefisien kuadrat variasi,

d. Varians yang mengacu variasi artifak,

e. Varianskore lasisesungguhnya,

f. Interval kepercayaan,

g. Dampak vaniasi reliabilitas.

\section{Analisis Data}

\section{Karakteristiksampel penelitian}

Sampel penelitian yeng dikaili dalam studi meta analisis memiliki karakteristik sebagaimana yang tercantum daiam tabel berikut: 


\begin{tabular}{|c|c|c|c|c|c|c|c|}
\hline \multirow{3}{*}{$\begin{array}{l}\text { No } \\
\text { Studi }\end{array}$} & \multirow{3}{*}{ Tahun } & \multirow{3}{*}{ Penelití } & \multirow{3}{*}{$\begin{array}{l}\text { Jenis Prestasi I } \\
\text { Performansi }\end{array}$} & \multicolumn{4}{|c|}{ Sampet } \\
\hline & & & & \multicolumn{3}{|c|}{ Jumlah N } & \multirow{2}{*}{ Karalkteristik } \\
\hline & & & & $\mathbf{P}$ & $w$ & $P+W$ & \\
\hline 1 & \multirow{3}{*}{2006} & \multirow{3}{*}{$\begin{array}{l}\text { Timothy D. Lackaye \& } \\
\text { Maka Mangalit }\end{array}$} & $\begin{array}{l}\text { Sense of } \\
\text { Coherence anak }\end{array}$ & 292 & 279 & 571 & $\begin{array}{l}\text { Anak } 124 \text { LD \& } \\
447 \text { NonLD }\end{array}$ \\
\hline 2 & & & Mood Positif & 292 & 279 & 571 & $\begin{array}{l}\text { Anak } 124 L D \& \\
447 \text { Non LD }\end{array}$ \\
\hline 3 & & & Harapan & 292 & 279 & 571 & $\begin{array}{l}\text { Anak } 124 \text { LD \& } \\
447 \text { Non LD }\end{array}$ \\
\hline 4 & 2006 & $\begin{array}{l}\text { Nocole Mills, Frank Pajares, } \\
\text { Carol Herron }\end{array}$ & $\begin{array}{l}\text { Kemahiran } \\
\text { Membaca \& } \\
\text { Menulis Prancis }\end{array}$ & 29 & 66 & 95 & $\begin{array}{l}\text { Mahasiswa } \\
\text { kursus Bahasa } \\
\text { Prancis }\end{array}$ \\
\hline 5 & 2005 & $\begin{array}{l}\text { Aurora P.Jackson, Ricard } \\
\text { Scheines }\end{array}$ & $\begin{array}{l}\text { Pengasuhan } \\
\text { Anak }\end{array}$ & - & $\dagger 88$ & 188 & $\begin{array}{l}\text { Ibu- lbu di } \\
\text { NewYork }\end{array}$ \\
\hline 6 & \multirow{2}{*}{2005} & \multirow{2}{*}{$\begin{array}{l}\text { Susan D. Holloway, } \\
\text { Sawako Suzuki, Yoko } \\
\text { Yamamoto, Kazuko } \\
\text { YBehrens }\end{array}$} & $\begin{array}{l}\text { Ingatan yang } \\
\text { posiltf pada anak }\end{array}$ & - & $\$ 16$ & 116 & $\begin{array}{l}\text { bu dengan } \\
\text { anak } \\
\text { prasekolah di } \\
\text { Jepang }\end{array}$ \\
\hline 7 & & & $\begin{array}{l}\text { Kepuasan dalam } \\
\text { menerima } \\
\text { dukungan sosial }\end{array}$ & - & 116 & 116 & $\begin{array}{l}\text { bu dengan } \\
\text { anak } \\
\text { prasekolah d } \\
\text { Jepang }\end{array}$ \\
\hline B & 2005 & $\begin{array}{l}\text { Jennifer EV Lloyd, John } \\
\text { walsh Manisheh Shehni } \\
\text { Yallagh }\end{array}$ & $\begin{array}{l}\text { Prestasi } \\
\text { Matematika }\end{array}$ & 80 & 81 & $16 t$ & $\begin{array}{l}\text { Murid SLTP of } \\
\text { British } \\
\text { Columbia }\end{array}$ \\
\hline 9 & \multirow{3}{*}{2004} & \multirow{3}{*}{ Mimi Bong } & $\begin{array}{l}\text { Prestasi Belajar } \\
\text { Bahasa Korea }\end{array}$ & - & - & 389 & SistreSITA \\
\hline 10 & & & $\begin{array}{l}\text { Prestasi Belajar } \\
\text { Bahasa hggris }\end{array}$ & - & - & 389 & SiswaSLTA \\
\hline 11 & & & $\begin{array}{l}\text { Prestasi Belajar } \\
\text { Bahasa inggris }\end{array}$ & - & - & 389 & Siswa \$LTA \\
\hline 12 & \multirow{3}{*}{2004} & \multirow{3}{*}{$\begin{array}{l}\text { Ivar Brater, Marlt S } \\
\text { Samuelstuen \& Hedge I } \\
\text { Stromso }\end{array}$} & Mastery Goa & 34 & 74 & 108 & $\begin{array}{l}\text { Mahasiswa } \\
\text { Kependidikan }\end{array}$ \\
\hline 13 & & & $\begin{array}{l}\text { Performance } \\
\text { Appro Goal }\end{array}$ & 34 & 74 & 108 & $\begin{array}{l}\text { Mahasiswa } \\
\text { Kependidikan }\end{array}$ \\
\hline 14 & & & Regulasi Dri & 34 & 74 & 108 & $\begin{array}{l}\text { Mahasiswa } \\
\text { Kependidikan }\end{array}$ \\
\hline 15 & \multirow{3}{*}{2004} & \multirow{3}{*}{$\begin{array}{l}\text { Ivar Braten, Marit } \mathbf{~} \\
\text { Samuelstuen \& Hedge I } \\
\text { Sromso }\end{array}$} & Mastery God & 65 & $\$ 13$ & 178 & $\begin{array}{l}\text { Mahasiswa } \\
\text { Manajemen }\end{array}$ \\
\hline 16 & & & $\begin{array}{l}\text { Performance } \\
\text { ApproGoal }\end{array}$ & 65 & 713 & 178 & $\begin{array}{l}\text { Mahasiswa } \\
\text { Manajement }\end{array}$ \\
\hline 17 & & & Regulasi Dhi & 65 & 113 & 178 & $\begin{array}{l}\text { Mahasiswa } \\
\text { Manajemen }\end{array}$ \\
\hline 18 & 2004 & $\begin{array}{l}\text { Terrance } G \text { Jakubowski, } \\
\text { Myron } H \text { Dembo }\end{array}$ & Self Regulation & 96 & 114 & 210 & Mahasiswa \\
\hline 19 & \multirow{3}{*}{2003} & \multirow{3}{*}{ Deboreh A Opacic } & $\begin{array}{l}\text { Nilal Hasil } \\
\text { (Oulcome Value) }\end{array}$ & 74 & 216 & 290 & $\begin{array}{l}\text { Mahasiswa } \\
\text { Kedokieran o } \\
\text { Pensyvania }\end{array}$ \\
\hline 20 & & & $\begin{array}{l}\text { Hasil yang } \\
\text { diharapkan } \\
\text { (Outcome } \\
\text { Expectancy) }\end{array}$ & 74 & $2+6$ & 290 & $\begin{array}{l}\text { Mahasiswa } \\
\text { Kedokteran d } \\
\text { Pensylvania }\end{array}$ \\
\hline 21 & & & Kinerja Klinik & 74 & 216 & 290 & $\begin{array}{l}\text { Mahasiswa } \\
\text { Kedokteran of } \\
\text { Pens ylvania }\end{array}$ \\
\hline 22 & 2002 & $\begin{array}{l}\text { Davld R Strauser, Kristi } \\
\text { Ketz, Jeanmarie Keim }\end{array}$ & $\begin{array}{l}\text { Work Personality } \\
\text { Profile Self } \\
\text { Report }\end{array}$ & 46 & 58 & 104 & $\begin{array}{l}\text { Peserta } \\
\text { program } \\
\text { rehabilitasi }\end{array}$ \\
\hline 23 & 2000 & $\begin{array}{l}\text { Robert Piorentine, Maureen } \\
\text { P. Hillhouse }\end{array}$ & Harepan Positif & - & - & 360 & $\begin{array}{l}\text { Peserto } \\
\text { rehabillasi }\end{array}$ \\
\hline
\end{tabular}




\section{Koefisien $r$ yang diperoleh}

\begin{tabular}{|c|c|c|c|c|}
\hline No. & $r x x$ & ryy & $r x y$ & $N X_{r} \times y$ \\
\hline 1 & 0.85 & 0.75 & 0.36 & 205.56 \\
\hline 2 & 0.85 & 0.74 & 0.5 & 285,5 \\
\hline 3 & 0.85 & 0.89 & 0.56 & 319.76 \\
\hline 4 & 0.79 & 0.79 & 0.78 & 74.1 \\
\hline 5 & 0.77 & 0.9 & 0.09 & 16.92 \\
\hline 6 & 0.82 & 0.88 & 0.35 & 40.6 \\
\hline 7 & 0.82 & 0.85 & 0.26 & 30.16 \\
\hline 8 & 0.85 & 0.86 & 0.14 & 22.54 \\
\hline 9 & 0.84 & 0.88 & 0.69 & 268.41 \\
\hline 10 & 0.84 & 0.9 & 0.66 & 256.74 \\
\hline 11 & 0.84 & 0.91 & 0.69 & 268.41 \\
\hline 12 & 0.85 & 0.7 & 0.28 & 30.24 \\
\hline 13 & 0.85 & 0.72 & 0.05 & 5,4 \\
\hline 14 & 0.85 & 0.75 & 0.28 & 30.24 \\
\hline 15 & 0.9 & 0.75 & 0.34 & 60.52 \\
\hline 16 & 0.9 & 0.73 & 0.4 & 71.2 \\
\hline 17 & 0.9 & 0.71 & 0.25 & 44.5 \\
\hline 18 & 0.92 & 0.79 & 0.433 & 90.93 \\
\hline 19 & 0.77 & 0.88 & 0.28 & 81.2 \\
\hline 20 & 0.77 & 0.88 & 0.48 & 139.2 \\
\hline 21 & 0.77 & 0.91 & 0.16 & 46.4 \\
\hline 22 & 0.88 & 0.85 & 0.32 & 33.28 \\
\hline $\boldsymbol{B}$ & 0.77 & 0.93 & 0.17 & 61.2 \\
\hline 24 & 0.65 & 0.91 & 0.569 & 81.936 \\
\hline 25 & 0.81 & 0.844 & 0.21 & 34.44 \\
\hline 26 & 0.91 & 0.788 & 0.7 & 245 \\
\hline 27 & 0.97 & 0.7 & 0.405 & 94,365 \\
\hline 28 & 0.73 & 0.71 & 0.89 & 89 \\
\hline 29 & 0.94 & 0.96 & 0.54 & 74.52 \\
\hline 30 & 0.87 & 0.97 & 0.36 & 239.76 \\
\hline
\end{tabular}

3. Pengujian Meta analisis dengan

Software Meta dengan Metode Schmidt-Huntermeialui program meta analisis versi 5.3 (Schwarzer, 1998).

Analysis by the Schmidt-Hunter-Method :

Population effect size (weighted mean if $=0.43115$

Explained variance $\quad r$-square $=0.18589$

Cormesponding $Z$ in Normal Distribution $=39.92460$

Significance

$p=0.00000$

Observed variance of effect sizes

Observed standard deviation

$=0.03659$

$=0.19129$

$95 \%$ confidence interval of pop. effect size:

from 0.069609 b 0.792692

Variance due b sampling error

$=0.00256$

Population or residual variance

$=0.03403$

Residual standard devialion

$=0.18446$ 
heterogeneous

Percentage of observed variance accounted

for by sampling error $=7.01 \% \rightarrow$

heterogeneous

Test of homogeneity

$\rightarrow$ hoterogeneous

Degrees of freedom

Significance

$$
\begin{aligned}
\text { Chi-square } & =428.02344 \\
\text { df } & =29 \\
p & =0.000000
\end{aligned}
$$

Resulls after Contection for Altenuation (based on reliabilities of measures)

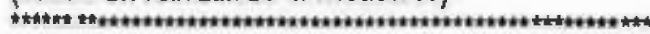

\# of $X$ variables with reliabilities : 30

\# of Yvariables whth reliabilities: 30

Mean of all square roots $[[x]$

$=0.91452$

Mean of all square rooks riy]

$=0.91016$

Variance of all square rools $[\{x x]$

$=0.00132$

Variance of all square rooks r [y]

$=0.00195$

"True" population effect size

$=0.51799$

Explained variance r(True) square

$=0.26831$

Corresponding Zin Normal Distribution $=49.20614$

Significance

Observed variance of effect sizes

$p=0.00000$

$=0.03659$

Variance due $b$ artifacts

$=0.00329$

Standard deviation due $b$ atifiacts

Population or residual variance

$=0.05738$

$=0.04806$

$=0.21923$

Residual slandard deviation

$95 \%$ confidence interval of true population effect

size:

From 0.08830 to 0.94767

Percent variance dre to unreliability $=1.99 \%$

Percent variance due b sampling error $=7.01 \%$

Percent variance due to al artifacts $=9.00 \%$

Mean standardized difference $\quad g=1,21111$

\section{HASIL.}

Berdasarkan uj meta analisis yang dilakukan, ditemukan bahwa:

1. Koefisien $r$ sesungguhnya adalah sebesar $0.51799(p=0.00000)$, dengan demikian hipotesa diterima.

2. Sumbangan variabel efikasi ciri terhadap variabel prestasi / performansi adalah sebesar $26,831 \%$.

3. Prosentase variansi yang disebabkan kesalahan pengambilan sampel adalah $7.01 \%$.

4. Prosentase variansi yang disebabkan oleh kesalahan pengukuran sebesar

\section{$1.99 \%$.}

5. Prosentase variansi yang đisebabkan oleh keđua artifak adalah $9 \%$

6. Interval kepercayaan $95 \%$ untuk r adalah antara 0.08830 sampai dengan 0.94767 .

7. Homogeneity of effect sizes (koefisien korelasi dari semua studi) menunjukkan hasil yang heterogen.

\section{PE MBA HASAN}

Berdasarkan hasil analisis data pada studi meta analisis tentang hubungan efikasi diri terhadap prestasi atau performansi, telah ditemukan korelasi positif yang sangat signifikan antara variabel-variabel tersebut, sehingga hipotesis dapat diterima. Hal ini sesuai dengan konsep teorl yang dikemukakan oleh para ahli, sejak pertama konsep efikasi đlri yang dikenalkan oleh Bandura đi tahun 1977 sampai sekarang.

Sumbangan efikasi diri sebesar $26,83 \%$ terhadap munculnya prestasi atau performansi menunjukkan adanya variabelvariabel lain yang diduga ikut berperan terhadap prestasi atau performansi (sebesar $73,17 \%$ ). Variabel lain itu bisa jadi hal-hal yang berasal dari dalam individu (kapasitas intelektual, minat, bakat, atau yang lain) maupun faktor luar (sosial budaya, dukungan sosial, dan lain-lain).

Prosentase variansi kedua artifak sebesar $9 \%$ menunjukkan kemungkinan bias kesalahan karena kekeliruan pengambllan sampel dan kesalahan pengukuran adalah kecil. Meskipun demikian, apabila dicermati leblh lanjut, terdapat perbedaan yang cukup mencolok antara prosentase varians yang disebabkan kesalahan pengambilan sampel dan kesalahan pengukuran. Prosentase varians karena kesalahan pengambilan sampel $(7,0)$ \%) jauh lebih besar daripada prosentase varians karena kesalahan pengukuran (1.99 $\%)$. Persoalan íni menjadi jelas ketika hasil analisis diperkuat oleh temuan bahwa Homogeneity of effoct sizes adalah heterogen dan interval kepercayaan $95 \%$ untuk $r$ yang sangat jauh rangenya $(0.08830$ sampai dengan 0.94767). Dengan demikian. 
ada indikasi bahwa hubungan efikasi diri dan prestasi memiliki variabel moderator yang perlu diteliti lebih lanjut. Secara teoritis, variabel-variabel yang diduga memiliki kaitan dengan korelasi ini antara lain karakteristik subjek (jenis Kelamin, usia, status, tingkat pendidikan, dan lain-lain), tipe studi (eksperimen laboratorium, studi lapangan) maupun pengukurannya (skala sikap, tes Kognitif, atau bentuk lain), seperti yang diungkapkan oleh Hunter \& Schmid (1990). Dalam studi ini, temuan tersebut bisa jad dikarenakan adanya variasi dalam variabel tergantung yang meliputi berbagai bidang.

Adanya lintas bidang yang dilakukan dalam pencarian korelasi melalui meta analisis memang sarat dengan risiko tidak bisa menemukan homogenity effect-size seperti yang diharapkan. Hal ini logis, karena pasti terdapat variasi dalam dimensi-dimensi efikasi diri, sebuah konstrak yang terdapat dalam efikasi diri. Sebagai contoh, performansi di bidang pendidikan pastilah memiliki dimensi yang berbeda dengan bidang yang lain. Dengan demikian, mestinya upaya meta analisis lintas bidang memerlukan kecermatan secara lebih khusus untuk menghindari bias secara konseptual.

\section{PENUTUP}

Pengujian secara meta analisis menunjukkan adanya hubungan yang sangat signifikan antara efikasi diri dan prestasi atau performansi individu dalam berbagai bidang, baik bidang pendidikan, klinis, industri maupun perkembangan. Hasil ini menunjukkan bahwa efikasi diri sangat bermanfaat untuk dimiliki oleh seseorang, demi mencapai prestasi ataupun performasi dalam haf apapun dengan baik, seperti halnya yang telah dikemukakan oleh Bandura (1977, 1982, 1986).

Dalam proses meta analisis ini juga ditemukan kemungkinan adanya variabel moderator dalam hubungan antara efikasi diri dan prestasi atau performansi. Berpijak dari sini $_{r}$ adalah penting untuk dilakukan evaluasi lanjutan yang lebih mendalam tentang keberadaan efikasi diri, sehingga dapat mengeksplorasi faktor-faktor yang lebih substansial.

\section{DAFTAR PUSTAKA}

Bandura, A. 1997. Self-Efficacy: Toward a Unifying Theory of Behavior Change. PsychologicalReviow,84, 191-215.

Bandura, A. 1982. Self-Efficacy Mechanism in Human Agency. American Psychologyst,37, 122-147.

Bandura, A 1986. Social Foundations of Thought and Action: A Social Cognitif Theory. Englewood Chifft, $\mathrm{N} J$ : Prentice Hall.

Bandura, A., \& Schunk, D. H. 1981. Cultivating Competence, Self-Efficacy and Intrinsic Interest Through Proximal Self-Motivation. Journal of personalyty and social Psychology, 41, 586-598. (Performance and Persistence)

Brater, I., Dkk. 2004. Do Students' SelfEfficacy Beliefs Moderate the Effects of Performance Goals on Self Regulatory Strategy Use?. Journal of Educational Psychology. 24.

Bong, M. 2004. Academic Motivation in SelfEfficacy, task Value, Achievement Goal Orientation, and Attributional Bellefs. Journal of Education research

Earley, P. C., \& Terry, R L. 1991. Delineating Goal and Efficacy Effects: A Test of Three Models. Joumal of Applied Psychology. 76, 81-98.

Fiorentine, R. \& Maureen, H. P. 2000. SelfEfficacy, Expectancies, and Abstinence Acceptance: Fur ther Evidence for the Addicted Self Model ofCessationofAlcohol and Drug Dependent Behavior. Journal of Drug and Alcohol Abuse. 26. 
Hackett, G., \& Betz, N. E. 1981. A SelfEfficacy Approach to Career Developm Women. Journal of Vocational Behavior, 18, 326-339.

Herman, K S. \& Nancy. E B. 2004. Path Models of Relationship of Instrumentality and Expressiveness to Social Self Eflicacy, Shyness, and Depressive Symtoms. J o u $r n$ a I Research. 51, 55 .

Holloway. S. D. 2005. Parenting Self-Eficacy Among Japanese Mothers. Journal of 78 Comparative Family Studies. 36, 61-

Hunter, J.E\& Schmidt, F.L.1990. Methods of Meta-Analysis. Sage Publications. Newbury Park.

Jaber, N. A \& Nayfeh . Q 1998. Students' Self-Efficacy of Computer Through The Use of Cognitive Thinking Style. Journal of instructional media. 25, 263.

Jakubowski, T. G, \& Myron, H. D. 2004. The Relationship of Self-Efficacy, Identity Style, and Stage of Change with Academic Self Regulation. Journal of College Reading and Leaming. 35.

Jackson. A. P. \& Ricard. S. 2005. Single Mother' Self-Efficacy, Parenting in the Home Environment, and Children's Development in a Two-Wave Study. Joumal of Social Work Research. 29, 7.

Lackaye, T. D., \& Malka, M. 2006. Comparisons of Achievement, and Self-Perceptions Among Students with Leaming Disabilities and Their Peers From Different Achievement Groups. Journal of Learning Disabilities. 39, 432.

Lent, R. W., Brown , S.D., \& Larkin, K. C. 1984. Relation of Self-Efficacy Expectation toAcademicAchievement and Percistence. Journal of
Counseling Psychology, 31, 356362. (Performance and Persistence)

Lent, R. W, Brown, S. D., \& Larkin, K C. 1986. Self-Efficacy in the Prediction of Academic Performance and Perceived Career Options. Joumal of Counseling Psychology, 33, 256269. (Performance and Persistence)

Lent, R.W., Frederick. G. L., \& kathleen. J. B. 1991. Mathematics Self-Efficacy: Sources and Relation to Science Based Career Choice. Joumal of Counseling Psychology. 38, 424430 .

Liyold, Jennifer, E. V. Dkk. 2005. Sex Differences in Performance Attribution, Self Efficacy, and Achievement in Mathematics: If I'm So Smart, Why Don't I Know It? . Journal of Education. 28, 384-41.

Luzzo, D. A. (1993). Value of Career Decision Making Self-efficacy in Predicting Career Decision Making Attitudes and Skills. Journal of Counseling Psychology. 40, 194 199.

Malphass, J. R., Harold. t. O. \& Dennis, $H$ 1999. Self-Regulation, Goal Orientation, SelfEfficacy, Worry, and Highstakes Math Achievement for Mathematically Gifted High School Student (1,2). Jornal of Rooper Review.21

Mills, N., Frank, P, \& Carol, H. 2006. A Revaluation of the Role of Anxiety: Self-Efficacy, Anxiety, and Their Relation of Reading and Listening Proficiency. Journal of Foreign Language Annals. 39, 276-296.

Mun,Y.Y. 2000. Role of Computer SelfEfficacy in Predicting User Acceptance and Use of Information Technology. myi@business.umd.edu 
Opacic, D. A 2003. The Relationship SelfEfficacy and Student Physician Assistant Clinical Performance. Joumal of Allied Health. 32, 158.

Pajares, Frank \& David, M. M. 1994. Role of Self-Efficacy and Self-Concept Beliefs in Mathematical Problem Solving: A Path Analysis. Joumal of Educational Psychology, 86, 193-203

Schunk, D.H. 1985 . Self-Efficacy and Classroom Learning. Psichology in the Schools, 22, 208-223.

Schunk, D.H. 1987. Self-Efficacy and Cognitive Acheivement. Paper Presented at the 95th Annual Convention of the American Psychological Association, New York.

Schwarzer (1998). Mefa analyses Program 5. 3. http://web. fu berlinde/gesund/qesu en $\mathrm{g} 1 / \mathrm{meta}$ e.htm.
Siegel, R. G., Galassi, J. P. \& Ware, W. B. 1985. A Comparison of Two Models for Predicting Mathematics Performance: Social Leaming versus MathAptitude anxiety. Journal of Counseling Psychology, 32, 531-538.

Strauser. D. R., Kristi .K., \& Jeanmarie K 2002. The Relationship between SelfEfficacy, Locus of Control and Work Personality. Joumal of Rehabilitation. 68,20 .

Tannenbaum. S. I., John, E M.: Enduro, S. \& A. Cannon B. 1991. Meeting Trainees' Expetations: The Influence of Training Fulfillment on the Developmentof Cornmitrnent, SelfEfficacy, and Motivation. Journal of Applied Psychology. 76, 759-769. 